\title{
THE PSYCHOLOGICAL PROFILE OF GROUP RHYTHMIC GYMNASTS
}

\author{
Mihaela MANOS ${ }^{*}$, Lavinia POPESCU ${ }^{1}$ \\ ${ }^{1}$ National University of Physical Education and Sport, Faculty of Physical Education and Sport, Bucharest, Romania \\ *Corresponding author: manosmihaela@yahoo.com
}

DOI: 10.35189/iphm.icpesk.2019.19

\begin{abstract}
Sports performance is determined by several factors, given the complexity of the human being, the conditions in which the athlete performs and has to cope with, but also the variety of methods and means that can be used to reach increased performance capacity. Starting from this idea, which has been highlighted by many sports specialists over the years, we address in this study some subjective phenomena that have determining characteristics for the performance capacity of rhythmic gymnasts. To objectify these phenomena, we determined the psychological profile of the investigated subjects $(8$ female gymnasts) with the help of behavioural-cognitive tests aimed to identify elements related to personality dynamics. The psychological tests were selected according to the specific features of the sports event in question and were administered under standard conditions. These tests and questionnaires were the following: Raven's Standard Progressive Matrices, Eysenck's Personality Inventory, Cattell's Anxiety Scale Questionnaire and Guilford-Zimmerman Temperament Survey. The obtained results have shown that the personality profile is harmoniously developed, being characterised by ambiversion, emotional stability and adaptation for all tested female gymnasts, who have a strong, realistic, balanced, thoughtful, persevering, sociable, self-confident and cooperative character. In conclusion, addressing the psychological preparation of athletes through a special plan, without ignoring their psychological profile, is an important condition that can positively influence the training process and the competitive performance of the group.
\end{abstract}

Keywords: psychological profile, psychological tests, group rhythmic gymnastics.

\section{Introduction}

Nowadays, achieving high performance requires not only exceptional biological characteristics, but also psychological skills, outstanding personality traits. In this context, knowing the athlete's personality in order to shape and develop it gains increasing weight in the specialised contemporary psychology.

According to Allport (1961), "personality is the dynamic organization within the individual of those psychophysical systems that determine his characteristic behaviour and thought" (p. 28), the author suggesting that human beings are both product and process, which means that people possess both an organized structure and the capability of change. Since personality uniquely influences cognitions, motivations and behaviours in various life situations, it represents an integral part of each individual.

Several theoretical frameworks of integrated personality have been developed so far (Cervone, 2004; Fleeson \& Jayawickreme, 2015), but empirical research is still in its early stages (Beckmann \& Wood, 2017). However, it has been acknowledged that situations are crucial to an integrated view of personality, because they have an impact on variations in cognitive, affective and behavioural responses of an individual. Thus, context-related variables should focus on the objective features and subjective perception of situations in a specific field of activity (i.e. task difficulty, task urgency, task support or task controllability) (Minbashian, Wood, \& Beckmann, 2010) for the facilitation of self-regulatory processes. The category of subjective landmarks includes psychological processes and phenomena, but also social aspects. Dragnea (1994) states that subjective phenomena are manifest and therefore observable, which facilitates the recording of their frequency, duration and effects. They can be measured by tests, questionnaires, inventories and different types of subtests that allow their objectification.

Gagne (2005) believes that, besides high sensorimotor abilities, personality is an important catalyst for success. Cox (2006) also states that success in sports activities is determined, on the one hand, by motor and physical abilities, and, on the other hand, by personality characteristics such as personality traits, cognitive characteristics, locus of control, goal orientation and so more. Although personality traits are not always consistently manifested in human behaviour, they are in a dynamic relation with other components of the personality system, i.e. basic tendencies, specific adaptations, self-concept (McCrae \& Costa, 2008). Moreover, they have a significant prediction and discriminant power with regard to several (socio-) psychological variables (including the sports-related ones) and allow more general insights (Weinberg \& Gould, 2007).

Nowadays, when the value of sports performance is constantly increasing, the coach has the task of influencing the athlete's personality structure, especially in attitudinal terms. However, apart from the coach, all those involved in the training and competitive performance of athletes (whether a coach, physician, psychologist or biochemist) should have a systemic view in order to comprehend the sports phenomenon in its whole complexity. 
Research tasks: determining the psychological profile of group rhythmic gymnasts through behavioural-cognitive psychological tests.

Research hypothesis: some subjective phenomena that have determining characteristics for the performance capacity can be controlled and objectified.

\section{Material and Methods}

Research subjects and period. Participants in this study were 8 group rhythmic gymnasts, senior members of the national team. The research was conducted between January and June 2014.

The research methods used were: documentation, paper and pencil tests (questionnaire, inventory), mathematical and statistical method, tabular and graphical methods.

\section{Personality tests and questionnaires}

The four tests (Raven's Standard Progressive Matrices, Eysenck's Personality Inventory, Cattell's Anxiety Scale Questionnaire and Guilford-Zimmerman Temperament Survey) were applied under standard conditions and aimed to identify elements related to the dynamics of personality. Their choice depended on both the specificity of the event and related psychological demands. The interpretation of psychological tests and other data obtained from observations, discussions and behaviour analysis was the most difficult but most important part of the work performed by the specialised psychologist. The detailed observations made by coaches with regard to the specific behaviour of gymnasts during the training sessions, competitions and recovery periods complemented these data, contributing to the achievement of a good psychological characterisation of each female athlete and the entire group as well.

1. Raven's Standard Progressive Matrices - Fluid intelligence

This is a multiple-choice test made up of 60 items used to assess mental ability associated with abstract reasoning or "fluid/crystallised intelligence" (according to Cattell, 1963). Initially published by Raven in 1938, the test includes increasingly difficult matching tasks that do not require language abilities. Specifically, the subject has to identify the missing element that completes a pattern (a visual geometric design). The standard form of the test consists of five sets (from A to E) of twelve matrices each, all presented in black and white, which are used as an indicator of general intelligence (abbreviated as "g") all over the world (Bilker et al., 2012). The g-factor variable measures the ability to think clearly and understand complex data, but also to store and reproduce information.

Therefore, the test provides insight into a subject's ability to perceive new patterns and relationships, solve problems and learn. It is a good predictor of success in educational settings, for both children and adults. The maximum score, namely 60 points, is converted into a standard score.

The scores correspond to a grade as follows:

- Grade I: intellectually superior - at or above the $95^{\text {th }}$ percentile;

- Grade II: above average - at or above the $75^{\text {th }}$ percentile; between the $90^{\text {th }}$ and $94^{\text {th }}$ percentile $-\mathrm{II}^{+}$.

- Grade III: intellectually average - between the $25^{\text {th }}$ and $75^{\text {th }}$ percentile; if above the $50^{\text {th }}$ percentile - III $^{+}$;

- Grade IV: below average - at or below the $25^{\text {th }}$ percentile;

- Grade V: intellectually impaired - at or below the $10^{\text {th }}$ percentile. ("Raven's Progressive Matrices", 2016)

2. Eysenck's Personality Inventory (Form A)

This is a self-report instrument measuring two independent dimensions of personality, namely ExtraversionIntroversion (E) and Neuroticism-Stability $(\mathrm{N})$. Extraversion describes differences between people in their social interactions, positive emotions, impulsivity and energy levels (Fielden, Kim, \& MacKenn, 2015). Extroverts are sociable, energetic, enthusiastic, positive, assertive etc., have a preference for more stimulating environments and tend to work well in groups, seeking to obtain satisfaction from the outside world. Introversion describes a state of being mainly interested in one's inner world. Introverts are more reflective, reserved, quiet, analytical, self-controlled etc., have a preference for less stimulating environments and take pleasure in solitary activities. Ambiversion is in-between the extraversion-introversion continuum. Ambivert people are moderately pleased with social interactions, but also spend time alone, their behaviour changing according to the situation. (Bhandari, 2018) Neuroticism involves high levels of anxiety and depression. Neurotic people cannot control their emotions and become easily upset in the presence of minor stressors. Emotionally stable people control well their emotions, are calm under pressure and feel uncomfortable only when confronted to major stressors. ("Eysenck's Personality Inventory", n.d.) 
The Eysenck's Inventory includes 57 "Yes-No" items and also a falsification scale for the detection of distorted responses - Lie (L) (Eysenck \& Eysenck, 1986). Each response is given 1 point. The total number of points represents the raw score as follows: 1-10 points - introvert, 11-17 points - ambivert, 18-24 points - extravert. The raw score related to the standard ( $0-10$ classes) is converted into a standard score.

The $\mathrm{E}$ score measures how much of an extravert a subject is: standard scores above 6 reveal extraversion, scores below 4 indicate introversion, while 4, 5 and 6 are considered to be average scores that correspond to ambiversion.

The $\mathrm{N}$ score measures how neurotic a subject is: standard scores above 6 indicate emotional instability, and those below 4, emotional stability.

The $\mathrm{L}$ score measures how socially desirable the subjects are trying to be in their responses: a score above 4-5 makes it impossible to validate the subject's response.

3. Cattell's Anxiety Scale Questionnaire

This 40-item scale measures the anxiety level in terms of high scores vs. low scores, using 5 personality factors:

- Q3 (perfectionism): perfectionistic, organized, self-disciplined vs. unexacting, flexible;

- C (emotional stability): emotionally stable, adaptive, mature vs. reactive, affected by feelings;

- L (vigilance): vigilant, suspicious, sceptical, wary vs. trusting, unsuspecting, accepting;

- O (apprehension): apprehensive, self-doubting, worried vs. self-assured, unworried, complacent;

- Q4 (tension): tense, high energy, driven vs. relaxed, placid, patient. (Conn \& Rieke, 1994)

After applying the test, three raw scores are obtained: the "A" score (total points for items 1-20) indicates hidden, indirect anxiety, the "B" score (total points for items 21-40) reveals manifest, symptomatic anxiety, and the total raw score, which is related to the standard (0-11 classes) and converted into a standard score, indicates the anxiety level. Following the interpretation of the raw score, several types of anxiety may result: placid - with low anxiety (level 0 ; $1 ; 2$ ), normal (anxiety level $3 ; 4 ; 5$ ), slightly anxious (level: $6 ; 7$ ), slightly neurotic but normal in terms of anxiety and manifest anxious type (level 8; 9; 10). Thus, $\mathrm{A}>\mathrm{B}$ indicates hidden, indirect anxiety, and $\mathrm{A}<\mathrm{B}$, manifest, symptomatic anxiety. $\mathrm{A}+\mathrm{B}=$ Total raw score.

4. Guilford-Zimmerman Temperament Survey

This personality inventory measures 10 traits identified by factor analysis, which are described as follows:

- General Activity (G): fast vs. slow;

- Restraint (R): self-controlled vs. impulsive;

- Ascendance (A): dominant vs. submissive;

- Sociability (S): sociable vs. shy;

- Emotional Stability (E): high vs. low;

- Objectivity (O): objective vs. subjective;

- Friendliness (F): friendly vs. aggressive;

- Thoughtfulness (T): think it through vs. act it out;

- Personal Relations (P): positive vs. negative;

- Masculinity (M). (Guilford \& Zimmerman, 1978) (Note: this trait was not included in our testing, since rhythmic gymnastics, like synchronised swimming, are traditionally called "feminine" sports.)

The test consists of 300 items, 30 for each of the 10 scales. For each item, subjects choose between "Yes", "No", "Cannot decide" (Terracciano, McCrae, \& Costa, 2006). Each response is given 1 point. Their sum is the raw score obtained for each factor concerned. Raw scores are related to the standard ( $0-10$ classes) and converted into standard scores. The interpretation of items is global, so the results obtained for different factors are not assessed separately, but in correlation with others, as well as with the individual's personal history and actual situational manifestations.

\section{Results}

Table 1. Raven's Standard Progressive Matrices - Fluid intelligence

\begin{tabular}{lcccc}
\hline \multicolumn{1}{c}{ Item no. } & Subjects & Score & Percentile & Scale \\
\hline 1. & S.M. & 57 & 100 & Intellectually superior (Grade I) \\
2. & V.E. & 57 & 100 & Intellectually superior (Grade I) \\
3. & V.A. & 60 & 100 & Intellectually superior (Grade I) \\
4. & G.M. & 55 & 100 & Intellectually superior (Grade I)
\end{tabular}


International Proceedings of Human Motricity/ ICPESK 2019

Supplementary Issue of Discobolul - Physical Education, Sport and Kinetotherapy Journal, 2019

\begin{tabular}{lcccc}
5. & T.R. & 55 & 100 & Intellectually superior (Grade I) \\
6. & G.A. & 55 & 100 & Intellectually superior (Grade I) \\
7. & A.M. & 59 & 100 & Intellectually superior (Grade I) \\
8. & H.G. & 53 & 90 & Above average $\left(\right.$ Grade $\left.\mathrm{II}^{+}\right)$ \\
\hline
\end{tabular}

Table 1 shows that the investigated athletes have superior intellectual capabilities, 7 gymnasts recording between 55 and 60 points, so above the $95^{\text {th }}$ percentile, and only one girl (H.G.) recorded a slightly lower score, namely 53 points, which placed her into the above-average category (between the $90^{\text {th }}$ and $94^{\text {th }}$ percentile).

So, with most athletes in the $100^{\text {th }}$ percentile and one athlete in the $90^{\text {th }}$ percentile, we can say that the tested gymnasts are able to think clearly, understand complex data, store and reproduce information, perceive new patterns and relationships, solve problems and easily learn motor tasks, also having imaginative, creative and productive potential. Rhythmic gymnastics needs such intellectual capabilities that underpin the entire preparation of athletes, because this sport highly engages their perceptive, sensory, kinaesthetic and attention-focusing abilities.

Table 2. Eysenck's Personality Inventory (Form A)

\begin{tabular}{|c|c|c|c|c|c|c|c|}
\hline \multirow{3}{*}{$\begin{array}{l}\text { Item } \\
\text { no. }\end{array}$} & \multirow{3}{*}{$\begin{array}{l}\frac{n}{0} \\
\frac{d}{2} \\
\ddot{E}\end{array}$} & \multicolumn{5}{|c|}{ Parameters } & \multirow{3}{*}{ Observations } \\
\hline & & \multicolumn{2}{|c|}{$\mathrm{N}$} & \multicolumn{2}{|c|}{$\mathrm{E}$} & \multirow{2}{*}{$\begin{array}{l}\mathrm{L} \\
\text { Standard } \\
\text { score }\end{array}$} & \\
\hline & & $\begin{array}{l}\text { Standard } \\
\text { score }\end{array}$ & $\begin{array}{l}\text { Raw score } \\
\text { (points) }\end{array}$ & $\begin{array}{l}\text { Standard } \\
\text { score }\end{array}$ & $\begin{array}{c}\text { Raw score } \\
\text { (points) }\end{array}$ & & \\
\hline \multirow[t]{2}{*}{1.} & S.M. & 1 & 3 & 6 & 12 & $3-4$ & $\begin{array}{c}\text { AMBIVERT - towards } \\
\text { introversion }\end{array}$ \\
\hline & & & & & & & Very good emotional stability \\
\hline 2. & V.E. & 3 & 7 & 6 & 12 & 5 & $\begin{array}{c}\text { AMBIVERT }- \text { towards } \\
\text { introversion } \\
\text { Emotional stability }\end{array}$ \\
\hline 3. & V.A. & 4 & 8 & 6 & 13 & $2-3$ & $\begin{array}{l}\text { AMBIVERT - towards } \\
\text { introversion } \\
\text { Emotional stability }\end{array}$ \\
\hline 4. & G.M. & 0 & 2 & 7 & 15 & $4-5$ & $\begin{array}{c}\text { AMBIVERT - towards } \\
\text { extraversion } \\
\text { Emotional stability }\end{array}$ \\
\hline 5. & T.R. & 7 & 14 & 5 & 10 & 2 & $\begin{array}{c}\text { INTROVERT } \\
\text { Emotional stability at the limit }\end{array}$ \\
\hline 6. & G.A. & 5 & 10 & 6 & 12 & 4 & $\begin{array}{c}\text { AMBIVERT - towards } \\
\text { extraversion } \\
\text { Emotional stability }\end{array}$ \\
\hline 7. & A.M. & 0 & 2 & 5 & 11 & 2 & $\begin{array}{c}\text { INTROVERT - towards } \\
\text { ambiversion } \\
\text { Very good emotional stability }\end{array}$ \\
\hline 8. & H.G. & 4 & 9 & 7 & 15 & 2 & $\begin{array}{c}\text { AMBIVERT - towards } \\
\text { extraversion } \\
\text { Emotional stability }\end{array}$ \\
\hline \multicolumn{2}{|c|}{ Mean } & 3 & 6.87 & 5.37 & 12.5 & & \\
\hline
\end{tabular}

Table 2 highlights the following aspects:

- For the $\mathrm{E}$ factor: 6 athletes are ambivert: of them, 4 have a tendency towards introversion (E score between 11 and 17 , the standard score 5 being closer to the maximum limit of introversion), and 2 have a tendency towards extraversion (the standard score being closer to the maximum limit of ambiversion). The other 2 girls are introvert $(\mathrm{E}<11 ; \mathrm{E}=11)$, with a tendency towards ambiversion, and one of them (T.R.) is at the 
borderline of emotional stability. The ambiversion characterising most of the girls is a sign that they are mentally balanced, so they are able to cope with various life situations, including those arising in training and competitions.

- For the $\mathrm{N}$ factor: 7 athletes have good emotional stability (with scores below 6), which allows them to experience success in their lives and sporting careers. An exception is the gymnast T.R., whose score is above 6.

- For the L factor: the athletes' responses were not distorted, since they recorded scores less than 4-5.

In conclusion, the tested gymnasts are generally objective and realistically interpret concrete situations, but with some subjectivity and a plus of imagination. In case of failure, they analyse the situation objectively. $50 \%$ of the investigated girls believe that they are responsible for the negative elements in their sports activity, which result from their less involvement in rigorous training, and do not blame others. The group becomes slightly nervous only in the presence of stressors (competition, strangers), when the athletes are not properly prepared and when they are to be tested.

As regards the gymnast T.R., who has problems with both the $\mathrm{E}$ and $\mathrm{N}$ factors, we think that this is not a defining feature for her, but rather a transitory state that can be overcome through a regulatory and self-regulatory programme.

Table 3. Cattell's Anxiety Scale Questionnaire

\begin{tabular}{|c|c|c|c|c|c|c|c|c|c|}
\hline \multirow[t]{2}{*}{$\begin{array}{c}\text { Item } \\
\text { no. }\end{array}$} & \multirow[t]{2}{*}{ Subjects } & \multirow{2}{*}{$\begin{array}{c}\text { Total raw } \\
\text { score } \\
\mathrm{A}+\mathrm{B}\end{array}$} & \multirow{2}{*}{$\begin{array}{c}\text { Total } \\
\text { standard } \\
\text { score }\end{array}$} & \multicolumn{5}{|c|}{$\begin{array}{l}\text { Parameters converted into partial standard } \\
\text { scores }\end{array}$} & \multirow{2}{*}{ Observations } \\
\hline & & & & Q3 & $\mathrm{C}$ & $\mathrm{L}$ & $\mathrm{O}$ & Q4 & \\
\hline 1. & S.M. & 20 & 2 & 6 & 3 & 4 & 6 & 1 & $\begin{array}{l}\text { Low level of } \\
\text { ANXIETY }\end{array}$ \\
\hline 2. & V.E. & 20 & 2 & 4 & 5 & 6 & 4 & 1 & $\begin{array}{l}\text { Low level of } \\
\text { ANXIETY }\end{array}$ \\
\hline 3. & V.A. & 23 & 3 & 6 & 3 & 6 & 5 & 3 & $\begin{array}{l}\text { Normal level of } \\
\text { ANXIETY }\end{array}$ \\
\hline 4. & G.M. & 19 & 2 & 6 & 3 & 6 & 3 & 1 & $\begin{array}{l}\text { Low level of } \\
\text { ANXIETY }\end{array}$ \\
\hline 5. & T.R. & 23 & 3 & 6 & 5 & 6 & 3 & 3 & $\begin{array}{l}\text { Normal level of } \\
\text { ANXIETY }\end{array}$ \\
\hline 6. & G.A. & 22 & 3 & 6 & 3 & 5 & 2 & 6 & $\begin{array}{l}\text { Normal level of } \\
\text { ANXIETY }\end{array}$ \\
\hline 7. & A.M. & 20 & 2 & 7 & 3 & 5 & 3 & 2 & $\begin{array}{l}\text { Low level of } \\
\text { ANXIETY }\end{array}$ \\
\hline \multirow[t]{2}{*}{8.} & H.G. & 21 & 2 & 4 & 5 & 6 & 4 & 2 & $\begin{array}{l}\text { Low level of } \\
\text { ANXIETY }\end{array}$ \\
\hline & fean & 21 & 2.37 & 5.62 & 3.75 & 5.5 & 3.75 & 2.37 & \\
\hline
\end{tabular}

The results obtained by gymnasts are shown Table 3 and Figure 1 as raw scores in the third column and in the form of standard scores for each test parameter in columns Q3, C, L, O and Q4. The total standard score indicates the level of anxiety.

For the Q3 parameter (perfectionism): the mean of the group is 5.62, which shows that the gymnasts are perseverant, effective in organized situations and able to work conscientiously. They have the potential and desire to constantly improve their skills, being aware that, in sport (as in life), learning never ends, and top performance can only be reached by commitment and hard work.

For the C parameter (emotional stability): the mean of the group is 3.75 , indicating that the gymnasts are emotionally stable, having enough maturity and power to control their feelings in challenging situations that often occur in life, as well as in sports training and competitions. Emotionality, this hidden part of our inner being, is not 
always totally controllable and much mental training is needed to master it, and this is even more difficult with young people, who are usually more vulnerable, because they have only partially experienced the complexity of life and competitive situations.

For the L parameter (vigilance): the mean of the group is 5.5, which reveals that the girls are vigilant, attentive to others' motives and intentions and sensitive to being misunderstood, thus proving maturity in thinking, intelligence and ability to focus on the tasks they have to accomplish in their sports activity and implicitly everyday life.

For the $\mathrm{O}$ parameter (apprehension): the mean of the group is 3.75, showing that the athletes are self-assured, so they seem to be content with themselves, which does not exclude the aspiration to become increasingly better in both life and the practiced sport. It is normal for the individual to be self-confident, but not excessively, because this would not be realistic since man is perfectible and life situations, as well as human reactions, are often unpredictable.

For the Q4 parameter (tension): the mean of the group is 2.37, a score revealing that the girls are quite relaxed when performing various tasks, generally manifesting a low level of anxiety as a result of their self-confidence, patience with themselves in case of failure and calmness in approaching various situations determined by internal or external factors. Relaxation is the key to stress reduction, good concentration and success in life and specifically the activity performed. But too much relaxation leads to lack of control due to overestimating one's own potential, which is why there must be a balance in everything.

Among the investigated girls, 5 have a low level of anxiety, and 3 have a normal level of anxiety, the overall score (2.37) placing the entire group into the low-anxiety category (which includes levels from 0 to 2 ).

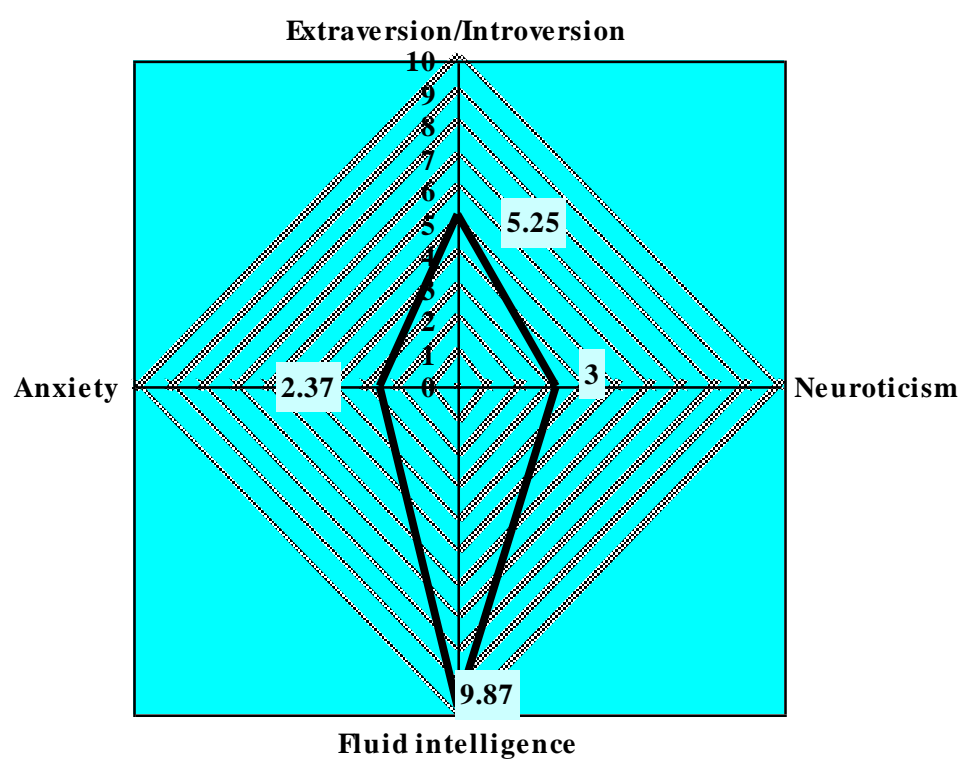

Figure 1. The profile of personality traits expressed in average scores (Eysenck's Personality Inventory, Raven's Standard Progressive Matrices, Cattell's Anxiety Scale Questionnaire)

Table 4. Guilford-Zimmerman Temperament Survey

\begin{tabular}{|c|c|c|c|c|c|c|c|c|c|c|c|c|c|c|c|c|c|c|c|}
\hline $\begin{array}{l}\stackrel{\dot{\Xi}}{\Xi} \\
\stackrel{\Xi \Xi}{\Xi}\end{array}$ & 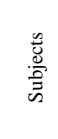 & G & 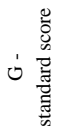 & $\mathrm{R}$ & $\propto \frac{0}{0}$ & A & 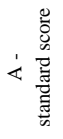 & $S$ & 的莸 & E & 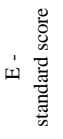 & O & 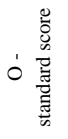 & F & 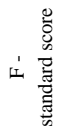 & $\mathrm{T}$ & 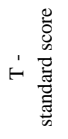 & $\mathrm{P}$ & 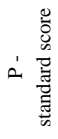 \\
\hline 1. & S.M. & 15 & 5 & 20 & 6 & 17 & 5 & 25 & 8 & 22 & 7 & 25 & 8 & 22 & 7 & 15 & 5 & 22 & 7 \\
\hline 2. & V.E. & 21 & 7 & 19 & 6 & 17 & 5 & 21 & 7 & 24 & 7 & 27 & 8 & 20 & 6 & 15 & 5 & 20 & 6 \\
\hline 3. & V.A. & 19 & 6 & 17 & 5 & 18 & 6 & 20 & 6 & 23 & 7 & 19 & 6 & 15 & 5 & 17 & 5 & 16 & 5 \\
\hline 4. & G.M. & 19 & 6 & 21 & 7 & 18 & 6 & 19 & 6 & 25 & 8 & 21 & 7 & 19 & 6 & 15 & 5 & 19 & 6 \\
\hline 5. & T.R. & 20 & 6 & 17 & 5 & 21 & 7 & 26 & 8 & 24 & 7 & 19 & 6 & 17 & 5 & 22 & 7 & 17 & 5 \\
\hline 6. & G.A. & 19 & 6 & 13 & 4 & 22 & 7 & 26 & 8 & 18 & 6 & 21 & 7 & 15 & 5 & 20 & 6 & 10 & 3 \\
\hline 7. & A.M. & 14 & 4 & 16 & 5 & 11 & 4 & 18 & 6 & 17 & 5 & 17 & 5 & 19 & 6 & 15 & 5 & 12 & 4 \\
\hline 8. & H.G. & 23 & 7 & 21 & 7 & 18 & 6 & 26 & 8 & 15 & 5 & 21 & 7 & 18 & 6 & 15 & 5 & 21 & 7 \\
\hline
\end{tabular}

The scores achieved by gymnasts for each of the 9 parameters reveal the following: 
- General Activity (G): good and very good levels (15-23 points), with scores ranging from 5 to 7 for most athletes;

- Restraint (R): optimum level for 7 athletes (17-21 points), with scores ranging from 5 to 7 , and below average for 1 athlete (13 points);

- Ascendance (A): good level for 7 athletes (16-20 points) and below average for 1 athlete (11 points);

- Sociability (S): within good and very good limits (18-26 points);

- Emotional Stability (E): good and very good levels (15-25 points);

- Objectivity (O): good level (17-27 points);

- Friendliness (F): good and very good levels for all athletes (9-22 points);

- Thoughtfulness (T): good and very good levels for all athletes (15-23 points);

- Personal Relations (P): very good level (10-21 points).

Figure 2 shows the average score of the group for each factor and the derived profile of personality traits.

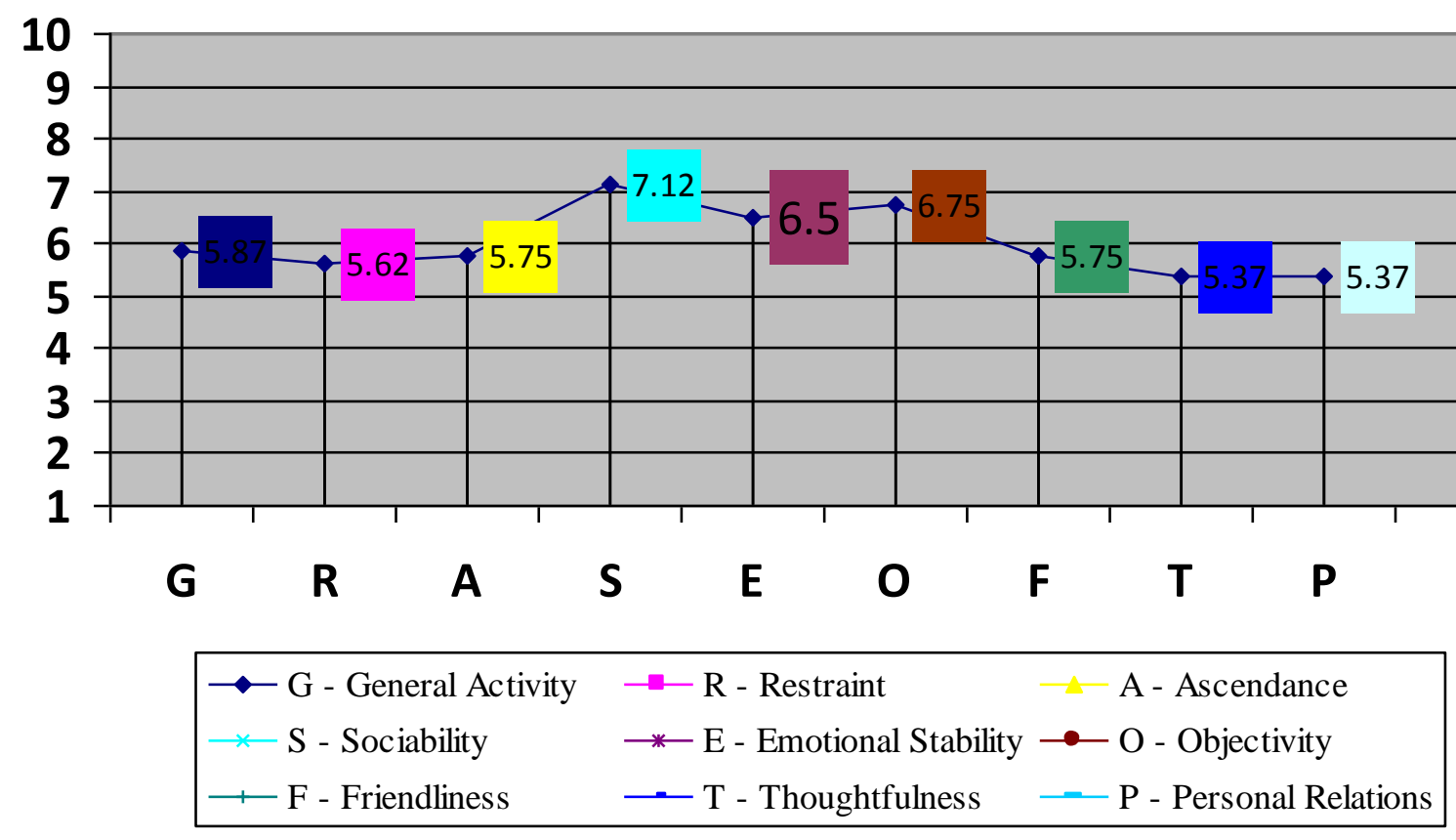

Figure 2. The profile of personality traits - Guilford-Zimmerman Temperament Survey - Average scores for the 9 factors

The personality profile is harmoniously developed, being characterised by ambiversion, emotional stability and adaptability. It reveals a strong, realistic, balanced, thoughtful, conscientious, persevering, sociable, self-confident and cooperative character for all group gymnasts.

\section{Conclusion}

Determining the level of involvement of intellectual and personality-related psychological processes, as well as the parameters of personality and intelligence, provides the opportunity to know, shape and exploit the individual and group psychological resources.

Addressing the psychological preparation of athletes through a special plan, without ignoring their psychological profile, is an important condition that can positively influence the training process and the competitive performance of the group.

\section{Authors' Contributions}

Both authors contributed equally to this study and should be considered as main authors. 


\section{References}

Allport, G. W. (1961). Pattern and growth in personality. New York: Rinehart and Winston.

Beckmann, N., \& Wood, R. E. (2017). Editorial: Dynamic personality science. Integrating between-person stability and within-person change. Frontiers in Psychology. https://dx.doi.org/10.3389\%2Ffpsyg.2017.01486

Bhandari, D. (2018). Personality types - Introvert and extrovert. Retrieved from https://www.medindia.net/patients/lifestyleandwellness/personality-types-introvert-and-extrovert.htm

Bilker, W. B., Hansen, J. A., Brensinger, C. M., Richard, J., Gur, R. E., \& Gur, R. C. (2012). Development of abbreviated nine-item forms of the Raven's Standard Progressive Matrices Test. Assessment, 19(3), 354-369. https://doi.org/10.1177/1073191112446655

Cattell, R. B. (1963). Theory of fluid and crystallized intelligence: A critical experiment. Journal of Educational Psychology, 54(1), 1-22. http://dx.doi.org/10.1037/h0046743

Cervone, D. (2004). The architecture of personality. Psychological Review, 111(1), 183-204. https://doi.org/10.1037/0033-295X.111.1.183

Conn, S. R., \& Rieke, M. L. (1994). 16PF Fifth Edition Technical Manual. Champaign, IL: Institute for Personality and Ability Testing, Inc.

Cox, R. H. (2006). Sport psychology: Concepts and applications. McGraw-Hill Humanities/Social Sciences/ Languages.

Dragnea, A. (1994). Măsurarea și evaluarea în educație fizică şi sport [Measurement and evaluation in physical education and sport]. București: Sport-Turism.

Eysenck's Personality Inventory (EPI). (n.d.). Retrieved from http://www.iluguru.ee/test/eysencks-personality-inventory-epi-extroversionintroversion/

Eysenck, H. J., \& Eysenck, S. B. G. (1986). Eysenck Personality Inventory Form A. London: Hodder and Stoughton.

Fielden, C., Kim, L. E., \& MacKenn, C. (2015). Extroversion. Retrieved from https://kundoc.com/pdf-extraversion-.html

Fleeson, W., \& Jayawickreme, E. (2015). Whole Trait Theory. Journal of Research in Personality, 56, 82-92. https://doi.org/10.1016/j.jrp.2014.10.009

Gagne, F. (2005). From gifts to talents. In R. J. Sternberg \& J. E. Davidson (Eds.), Conceptions of giftedness ( $2^{\text {nd }}$ ed.) (pp. 98-119). New York: Cambridge University Press.

Guilford, J. P., \& Zimmerman, W. S. (1978). The Guilford-Zimmerman Temperament Survey: Manual of instructions and interpretations. Beverly Hills, CA: Sheridan Psychological Services, Inc.

McCrae, R. R., \& Costa, P. T. (2008). The Five-Factor Theory of Personality. In O. P. John, R. W. Robins, \& L. A. Pervin (Eds.), Handbook of personality: Theory and research ( $3^{\text {rd }}$ ed.) (pp. 159-181). New York: The Guilford Press.

Minbashian, A., Wood, R. E., \& Beckmann, N. (2010). Task-contingent conscientiousness as a unit of personality at work. Journal of Applied Psychology, 95(5), 793-806. https://doi.org/10.1037/a0020016

$\begin{array}{lllll}\text { Raven's } & \text { Progressive } & \text { Matrices. } & \text { (2016). } & \text { Retrieved }\end{array}$ https://www.scribd.com/doc/306024370/Ravens-Progressive-Matrices

Terracciano, A., McCrae, R. R., \& Costa Jr., P. T. (2006). Longitudinal trajectories in Guilford-Zimmerman Temperament Survey Data: Results from the Baltimore Longitudinal Study of Aging. The Journals of Gerontology. Series B, Psychological Sciences and Social Sciences, 61(2), 108-116. https://dx.doi.org/10.1093\%2Fgeronb\%2F61.2.p108

Weinberg, R. S., \& Gould, D. (2007). Foundations of sport and exercise psychology (4 ${ }^{\text {th }}$ ed.). Champaign, IL: Human Kinetics. 